\title{
Polybenzoic Acid Modified Carbon Paste Electrode as an Electrochemical Sensor for the Determination of Uric Acid in the Presence of Ascorbic Acid and Dopamine - A Voltammetric Study
}

\author{
V. PRABHAKARA RAO, Y. VEERA MANOHARA REDDY, \\ P. JEEVAN JYOTHI, S. KIRANMAI and G. MADHAVI*
}

Department of Chemistry, Sri Venkateswara University, Tirupathi-517502, Andhra Pradesh, India

gmchem01@gmail.com

Received 6 March 2016 / Accepted 19 March 2016

\begin{abstract}
Uric acid (UA) detection is quite important in humans as high blood concentrations of UA called Hyperuricemia can lead to Gout, diabetes and formation of kidney stones etc. In the present work, a sensitive and selective method is presented for the voltammetric determination of UA in the presence of ascorbic acid (AA) and dopamine (DA) using a carbon paste electrode (CPE) modified with benzoic acid in $0.1 \mathrm{M}$ phosphate buffer solution (PBS) of $\mathrm{pH} 7$ by electropolymerisation. The obtained poly(benzoic acid) modified carbon paste electrode (PBA/CPE) showed excellent electro catalytic activity for the selective detection of UA in the presence of AA and DA and it also showed good reproducibility. Its sensitivity increased 2.33 folds for the detection of UA compared to bare carbon paste electrode (BCPE). Effect of variation of scan rate on the peak current indicated that the electrode process is both diffusion controlled and adsorption controlled. The detection limit (LOD) and quantification limit (LOQ) of the present technique were found to be $3.33 \times 10^{-7} \mathrm{M}(0.333 \mu \mathrm{M})$ and $1.11 \times 10^{-6} \mathrm{M}(1.11 \mu \mathrm{M})$ respectively for UA. pH effect suggested that equal number of protons and electrons were involved in the electrochemical oxidation of UA. The percentage of recovery of UA in real sample analysis i.e. in human urine is quite good and was found to be $100.5 \%$ using PBA/CPE. Thus, the selectivity, reproducibility and sensitivity of the PBA/CPE provide a good possibility for applying the technique in the routine analysis of selected class of electro active biomolecules.
\end{abstract}

Keywords: Dopamine, Ascorbic acid, Uric acid, Cyclic voltammetry, Differential pulse voltammetry

\section{Introduction}

Uric acid (2, 6, 8-trihydroxy purine) is the final oxidation product of purine metabolism in the human body ${ }^{1,2}$. The electro active UA (uric acid) can be irreversibly oxidized in aqueous solution and the major product of oxidation is allantoin ${ }^{3,4}$. This is one of the major products monitored in urine and blood. UA concentration changes are associated with the altered metabolism of 
purines that are related to numerous illnesses and physiological disorders ${ }^{5}$. Therefore, its determination in physiological fluids is necessary in the diagnosis and treatment of diseases such as hyperuricemia, gout, Lesch-Nyhan syndrome ${ }^{6}$ and heavy hepatitis. UA is also a marker for renal failure as well as toxicity. Hence, it is very important to develop effective techniques to determine the presence of UA in urine and blood. In recent years, various techniques have been employed for quantification of UA including fluorescence ${ }^{7}$, specrophotometry ${ }^{8,9}$, highperformance liquid chromatography (HPLC) $)^{10}$, flow injection ${ }^{11}$, capillary electrophoresis ${ }^{12}$ and electrochemical methods ${ }^{13,14}$. However, in the assay of UA, the electrochemical methods suffer from inferior selectivity because of the presence of AA and DA, as these coexist with UA in the physiological fluids and whose oxidation potentials always are close to $\mathrm{UA}^{15}$. Several attempts have been made to separate the oxidation peak potentials of UA, AA and DA ${ }^{16,17}$ electrochemically. Among these methods, using electro active polymer coated electrode, to determine UA in the presence of AA and DA displayed excellent selectivity and sensitivity. For some time CPEs modified with different materials are also widely used for the said purpose. CPEs were first reported in 1958 by Adams ${ }^{18}$. Science then it is being widely used in electrochemical research due to its often cited advantages of low ohmic resistance, large potential window and ease of modification ${ }^{16,19}$. Ease of the modification is one of the valuable features of CPE as this process gives well developed surface for CPE, which has a high adsorbptivity for the substances ${ }^{20}$.

In the present study, CPE was modified with benzoic acid by electropolymerisation using cyclicvoltammetry $(\mathrm{CV})$ in $0.1 \mathrm{M}$ PBS of $\mathrm{pH} 7$ in the potential window of $-0.8 \mathrm{~V}$ to $1.2 \mathrm{~V}$. The prepared PBA/CPE showed an excellent electro catalytic activity for the oxidation of UA, AA and DA. The results indicate that the modified electrode could be used to detect UA in the presence of AA and DA in routine analysis without any problem with greater sensitivity, selectivity and reproducibility.

\section{Experimental}

Uric acid and benzoic acid were obtained from Himedia chemical company. Dopamine hydrochloride and ascorbic acid were purchased from Merck. All other chemicals used in this investigation were of analytical grade and used without further purification. The supporting electrolyte used for all experiments was $0.1 \mathrm{M}$ phosphate buffer solution. It was prepared by mixing $0.2 \mathrm{M}$ sodium dihydrogen phosphate $\left(\mathrm{NaH}_{2} \mathrm{PO}_{4}\right)$ and disodium hydrogen phosphate $\left(\mathrm{Na}_{2} \mathrm{HPO}_{4}\right)$ stock solutions in appropriate quantities. The aqueous solutions were prepared with double distilled water.

\section{Instrumentation}

CHI610D electrochemical analyser controlled by a personal computer was used for cyclicvoltammetric (CV) and differential pulse voltammetric (DPV) measurements. A conventional three electrode cell was used for the investigation. Standard calomel electrode (SCE) was used as a reference electrode, a bare and poly (benzoic acid) modified carbon paste electrodes as working electrodes and a platinum wire as counter electrode. Systronics made digital $\mathrm{pH}$ metre MKV1 was used for the $\mathrm{pH}$ measurements of the solutions. The surface morphology of BCPE and PBA/CPE were studied using scanning electron microscopy (SEM).

\section{Preparation of bare carbon paste electrode}

Graphite powder and silicon oil were taken in the ratio of 70:30 (w/w) and thoroughly hand mixed using an agate mortar to get a homogeneous paste. This paste was filled in to a hole 
$3 \mathrm{~mm}$ internal diameter and $5 \mathrm{~mm}$ depth made in a PVC rod on one side. The electrical contact to the paste was provided with a copper wire and the surface of the electrode was smoothened by polishing on a weighing paper. Thus, the BCPE was prepared.

Preparation of poly(benzoic acid) modified carbon paste electrode

The BCPE prepared as described above was immersed in $1 \mathrm{mM}$ benzoic acid solution in $0.1 \mathrm{M}$ PBS of $\mathrm{pH} 7$ for electroploymerisation. The electroploymerisation was enforced under sweeping from $-0.8 \mathrm{~V}$ to $1.2 \mathrm{~V}$ at the scan rate of $50 \mathrm{mV} / \mathrm{S}$ for 15 cycles using cyclic voltammetry. The electropolymerisation was successful with the formation of a thin polymer layer on the surface of the CPE. The polymer layer formation was confirmed with SEM. After polymerization, the modified electrode was thoroughly rinsed using double distilled water to remove any traces of unreacted benzoic acid and used for the determination of UA in the presence of AA and DA.

\section{Results and Discussion}

\section{Electropolymerisation of benzoic acid at the surface of carbon paste electrode}

As described above electropolymerisation was carried out on BCPE to get PBA/CPE. The resulting $\mathrm{CV}$ is shown in Figure 1. In the first cycle a broad voltammogram was obtained, which went on decreasing from second cycle and stabilized at the end. The gradual decrease of voltammograms as the number of cycles increases shows that benzoic acid was deposited on the surface of CPE. The stabilization at the end indicated that the polymer film formed adjusted itself well on the $\mathrm{CPE}^{21}$.

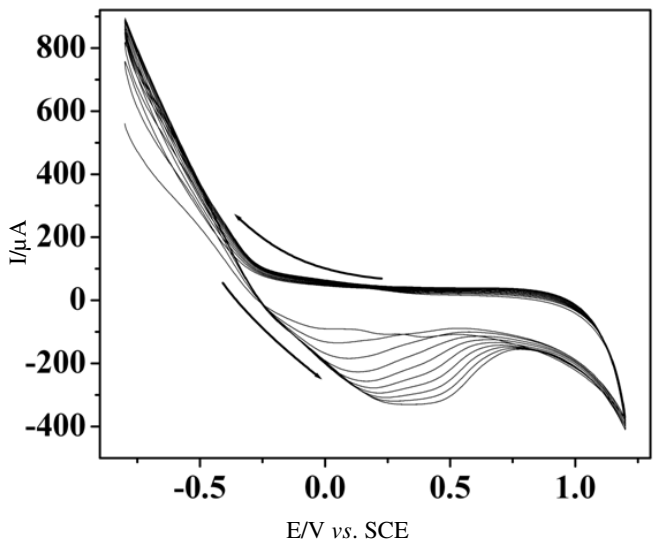

Figure 1. Cyclic voltammogram for the electropolymerisation of benzoic acid on bare carbon paste electrode for 10 cycles at the scan rate of $50 \mathrm{mV} / \mathrm{S}$

The formation of polymer film of benzoic acid was confirmed with SEM. Figure 2(A) and 2(B) shows the surface morphology of BCPE and PBA/CPE. From the Figure 2(A) it is evident that surface of $\mathrm{BCPE}$ is uneven with flakes of graphite seen, whereas the surface of $\mathrm{PBA} / \mathrm{CPE}$ is smooth and quite even as shown in Figure 2(B).

The reaction mechanism of formation of polymer film of benzoic acid can be explained as follows. One of the double bonds in the benzene ring of benzoic acid gets cleaved homolytically to get a biradical at the surface of CPE and the free radicals then combine with the surface of CPE and the other benzoic acid molecules rapidly resulting in the formation of a stable polymer film as shown in Scheme 1. 

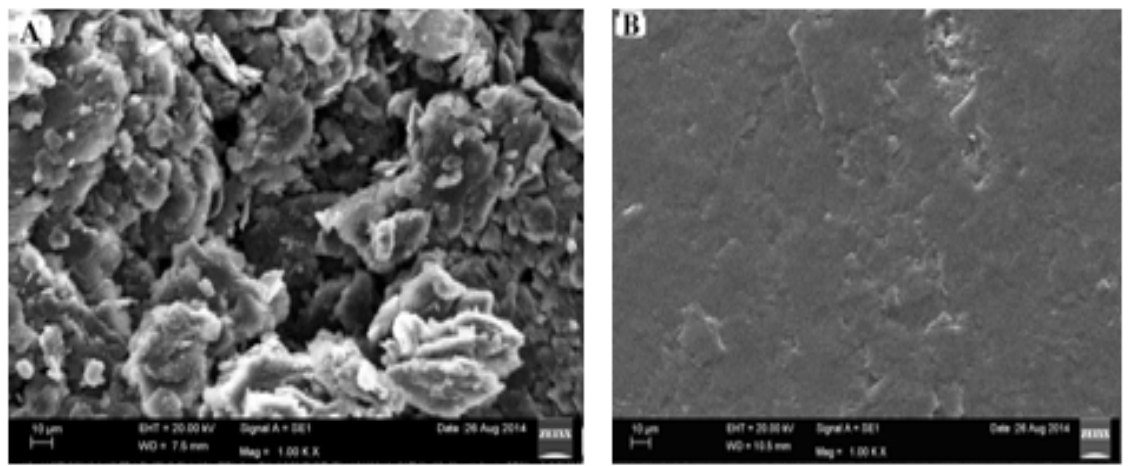

Figure 2. Scanning electron microscopic images of A) bare carbon paste electrode, B) poly(benzoic acid) modified carbon paste electrode

1.Benzoic acid biradical formation<smiles>O=C(O)C1=CCCC=C1C=Cc1ccc(C(F)(F)F)cc1</smiles>

2.Bonding to CPE<smiles>CC1CCC(C)C(C)C1</smiles>

\section{Polymerisation at CPE}

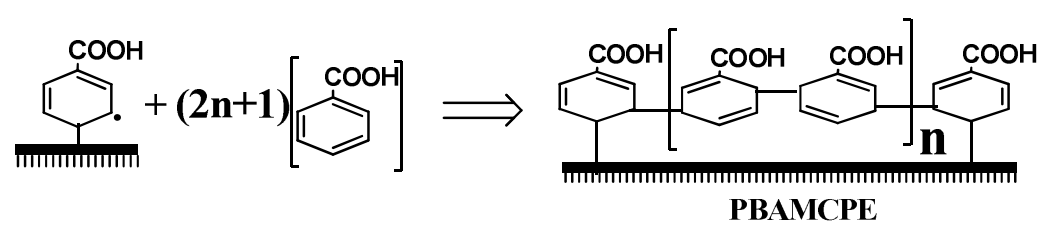

Scheme 1. Polymerisation mechanism of benzonic acid

Investigation of effect of number of cycles of polymerization on sensitivity for the determination of UA was carried out. It was found that for 15 cycles of polymerization, the electrode showed maximum sensitivity for UA in $\mathrm{pH} 7$ PBS. Figure 3(A) shows the effect of number of cycles of polymerization on sensitivity whereas Figure 3(B) shows the corresponding CVs. It is visible from Figure 3(A) that up to 15 cycles of polymerization the anodic peak current increased, at 15 cycles the current response was maximum and after that the current response decreased. The initial increase of current may be due to gradual covering of the surface of BCPE with poly (benzoic acid) film and thus leading to gradual increase in the number of active sites of $-\mathrm{COOH}$ functional group. This functional group enhances the rate of oxidation of UA by interacting with it through $\mathrm{H}$-bonds. This leads to increase in current. This is shown in Scheme 2. At 15 cycles probably the entire surface was covered with polymer film of benzoic acid which meant that there was maximum number of $-\mathrm{COOH}$ active sites. Hence, at this point there was maximum current response. However, after 15 cycles the current decreased as there was no further increase of number of active sites and also the thickening of polymer layer might have decreased the permeability. 

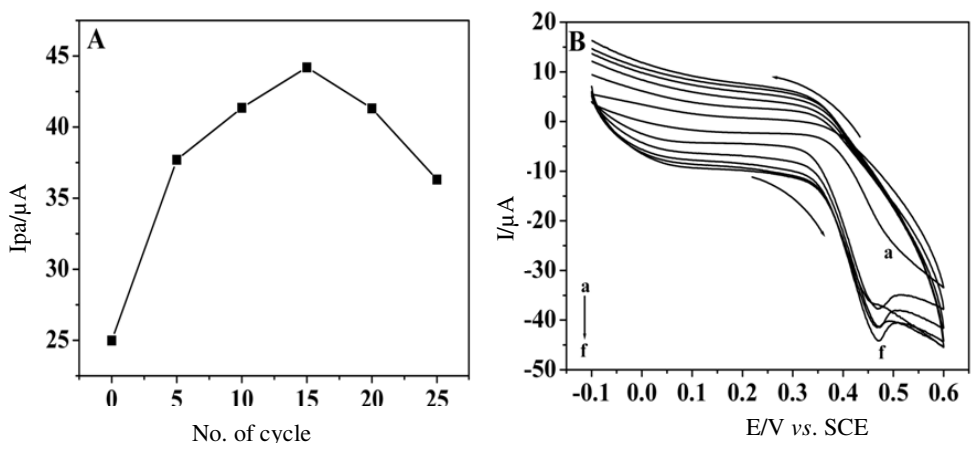

Figure 3. (A) Dependence of anodic peak current on the number of cycles of polymerisation for uric acid detection, (B) Voltammograms for the detection of uric acid depending on the number of cycles of polymerization (a-f : 0, 5, 10, 15, 20 and 25 cycles)

\section{Electrochemical characterization of poly(benzoic acid) modified carbon paste electrode}

The electrochemical response of potassium ferrocyanide at bare and PBA/CPE were recorded in the potential range of $-0.2 \mathrm{~V}$ to $0.6 \mathrm{~V}$ at $50 \mathrm{mV} / \mathrm{s}$ scan rate and is shown in Figure 4. The electrochemical response was poor at BCPE (solid line curve) with reversible behavior in $1 \mathrm{M} \mathrm{KCl}$ as supporting electrolyte. However, the response at PBA/CPE (dashed line curve) improved by 1.42 folds. At BCPE, the anodic (Epa) and cathodic (Epc) peak potentials were $0.409 \mathrm{~V}$ and $0.237 \mathrm{~V}$ respectively. The separation of redox peak potentials $(\triangle \mathrm{Ep})$ was $0.172 \mathrm{~V}$ and the ratio of peak currents Ipa/Ipc was 1.50. At PBA/CPE, the peak currents increased many folds whereas separation of peak potentials $(\Delta \mathrm{Ep})$ remained unchanged and Ipa/Ipc was 1.43. The Ipa/Ipc value at PBA/CPE (1.43) approached more close to one than that of BCPE (1.5). These facts indicate that the redox process of potassium ferrocyanide has become more reversible at PBA/CPE.

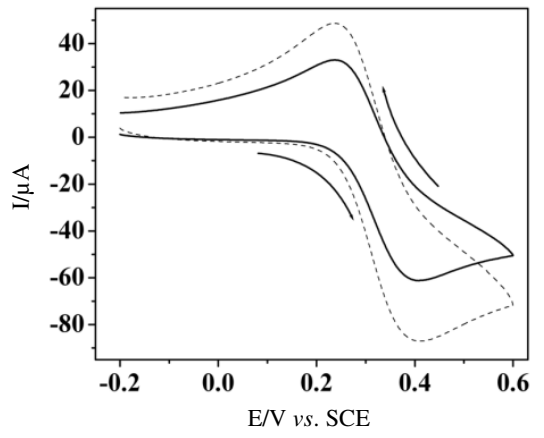

Figure 4. Cyclic voltammogram of $1 \mathrm{mM}$ potassium ferrocyanide solution in $1 \mathrm{M} \mathrm{KCl}$ at bare carbon paste electrode (solid line curve) and poly(benzoic acid) modified carbon paste electrode (dashed line curve) at the scan rate of $50 \mathrm{mV} / \mathrm{s}$

In order to obtain the effective surface areas of BCPE and PBA/CPE, CV experiments were performed with both the electrodes separately at various scan rates using $1 \mathrm{mM}$ potassium ferrocyanide solution. Randles-Sevick equation (eq.1) was used to calculate the effective surface areas.

$$
\mathrm{Ip}=2.69 \times 10^{5} \times \mathrm{D}^{1 / 2} \times \mathrm{A} \times v^{1 / 2} \times \mathrm{n}^{3 / 2} \times \mathrm{C}_{0}
$$


For potassium ferrocyanide $\left(\left[\mathrm{Fe}(\mathrm{CN})_{6}^{-3}\right] /\left(\left[\mathrm{Fe}(\mathrm{CN})_{6}^{-4}\right]\right), n\right.$ (number of electrons transferred) $=1, \mathrm{C}_{0}$ (concentration of the solution) $=1 \times 10^{-6} \mathrm{~mol} . \mathrm{cm}^{-3}$ and $\mathrm{D}$ (diffusion coefficient $)=1.6558 \times 10^{-4} \mathrm{~cm}^{2} \mathrm{~s}^{-1}$. Using these values effective surface areas of BCPE and PBA/CPE were calculated to be $0.3080 \mathrm{~cm}^{2}$ and $0.4479 \mathrm{~cm}^{2}$ respectively indicating that polymerization has increased the surface area. Hence, this leads to amplified anodic and cathodic peak currents for potassium ferrocyanide at PBA/CPE.

Electro catalytic response of UA at poly(benzoic acid) modified carbon paste electrode

UA being easily oxidisable, its voltammogram was recorded in the potential range of $-0.1 \mathrm{~V}$ to $0.6 \mathrm{~V}$ using $0.1 \mathrm{PBS}$ as a supporting electrolyte at $50 \mathrm{mV} / \mathrm{S}$ scan rate and is shown in Figure 5(A). Solid line curve represents the voltammetric response at BCPE and dashed line curve represents the response at PBA/CPE for $1 \mathrm{mM}$ UA solution. There is clear improvement in the redox peak currents at PBA/CPE compared to BCPE by 2.33 folds. At BCPE, UA underwent nonreversible oxidation at Epa of $0.460 \mathrm{~V}$. At PBA/CPE the electrolytic process became reversible with $\triangle \mathrm{Ep}$ of $0.78 \mathrm{~V}$. Enhancement in the redox peak currents for UA at PBA/CPE could be attributed to hydrogen bond formation at modified electrode between $-\mathrm{COO}^{-}$active sites on modified electrode and $-\mathrm{NH}$ hydrogens in UA molecules. This mechanism is shown in Scheme 2.
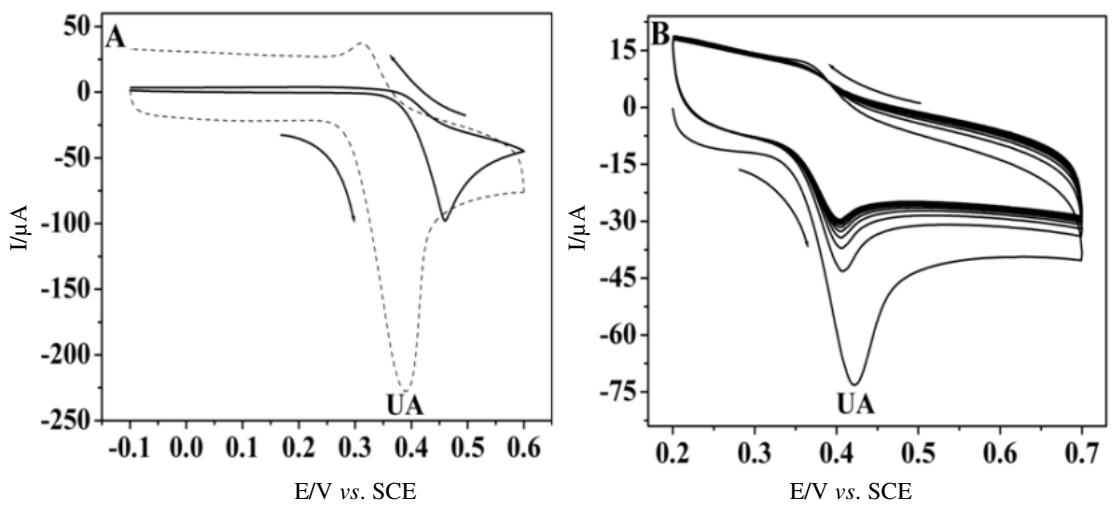

Figure 5. (A) Cyclic voltammogram of $1 \mathrm{mM}$ uric acid in $0.1 \mathrm{M}$ phosphate buffer solution of pH 7 at bare carbon paste electrode (solid line curve) and poly (benzoic acid) modified carbon paste electrode (dashed line curve) at $50 \mathrm{mV} / \mathrm{s}$ scan rate, (B) Cyclic voltammograms of $1 \mathrm{mM}$ uric acid for 15 multiple cycles in $0.1 \mathrm{M}$ phosphate buffer solution of $\mathrm{pH} 7$ at $50 \mathrm{mV} / \mathrm{s}$ scan rate to test the stability of the electrode

The stability and reproducibility of the PBA/CPE was tested by running 15 sweep cycles in the potential window of $0.1 \mathrm{~V}$ to $0.6 \mathrm{~V}$ for $1 \mathrm{mM}$ UA solution in $0.1 \mathrm{M} \mathrm{pH} 7 \mathrm{PBS}$ at $50 \mathrm{mV} / \mathrm{s}$ scan rate. As shown in Figure 5(B), the CV curves, except for first few cycles, were overlapping indicating that the electrode is fairly stable for the determination of UA.

\section{Effect of scan rate}

The effect of scan rate was studied to understand the electrode process and verify whether diffusion is the only controlling factor for mass transport or not. Hence, the voltammogram of UA was recorded by varying the scan rate from $50 \mathrm{mV} / \mathrm{s}$ to $400 \mathrm{mV} / \mathrm{s}$ at PBA/CPE in the potential range of $-0.1 \mathrm{~V}$ to $0.8 \mathrm{~V}$. The $\mathrm{CV}$ as in Figure $6(\mathrm{~A})$ showed an increase in both anodic (Ipa) and cathodic (Ipc) peak currents of UA with an increase in scan rate. The plots 
of Ipa $v s$. scan rate $(v)\left(\right.$ Ipa $\left.=2.83 \times 10^{-4} \times v+9.237 \times 10^{-5}\right)$ Figure $6(\mathrm{~B})$ and Ipa $v s$. square root of scan rate $\left(V_{v}\right)\left(\right.$ Ipa $\left.=2.49498 \times 10^{-4} \times \sqrt{ } v+4.23382 \times 10^{-5}\right)$ Figure $6(\mathrm{C})$ were constructed and found to be linear with correlation coefficients $(\mathrm{R})$ of 0.98251 and 0.99387 respectively. It indicates that the electrode reaction is both adsorption and diffusion controlled. Also, the slope of $\log I p a$ vs. $\log v$ Figure 6(D) was 0.58639 which is larger than the theoretical expected value of 0.53 for purely diffusion controlled process ${ }^{22}$ which again emphasizes the fact that the electrode process is both adsorption and diffusion controlled.

1. Interation of Uric acid with BAMCPE:

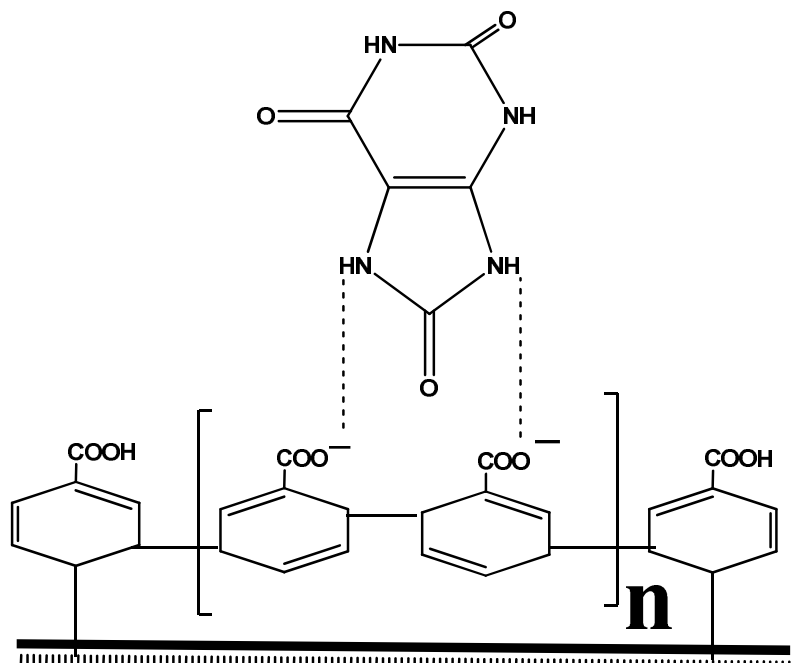

BAMCPE

2. Oxidation of uric acid:<smiles>Cn1c(=O)[nH]c(=O)c2[nH]c(=O)[nH]c(=O)c21</smiles>
Uricaid

Scheme 2
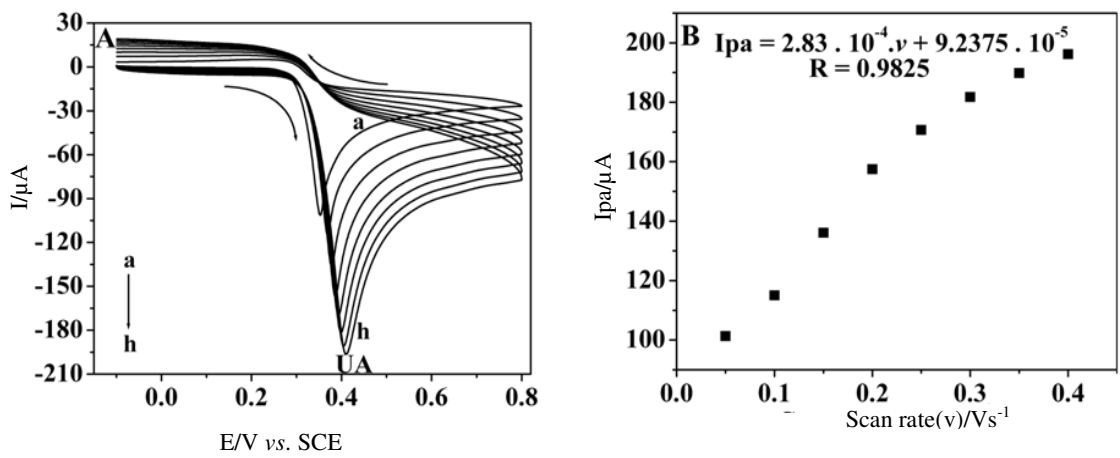

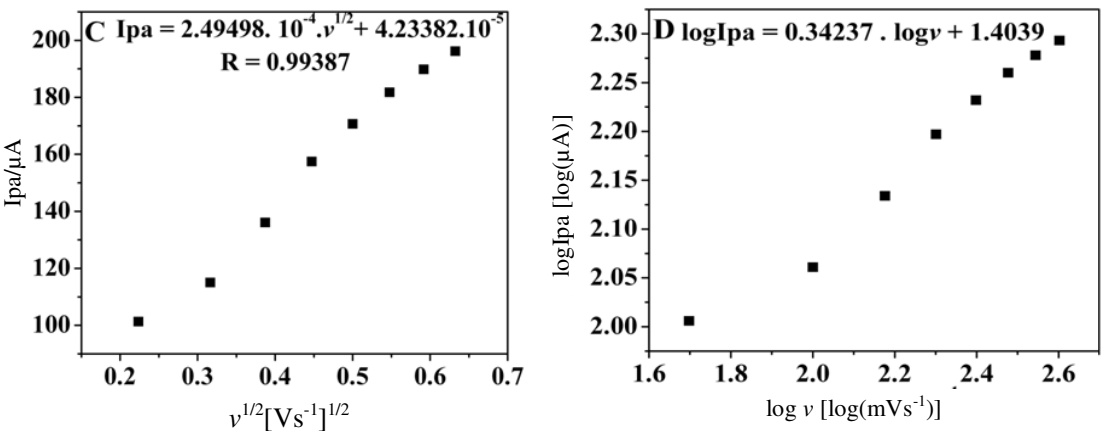

Figure 6. (A) Cyclic voltammograms of $1 \mathrm{mM}$ uric acid on poly(benzoic acid) modified carbon paste electrode at different scan rates (a-h : 50, 100, 150, 200, 250, 300, 350 and 400 $\mathrm{mV} / \mathrm{s}$ ) in $0.1 \mathrm{M}$ phosphate buffer solution of $\mathrm{pH} \mathrm{7,} \mathrm{(B)} \mathrm{The} \mathrm{plot} \mathrm{of} \mathrm{anodic} \mathrm{peak} \mathrm{current}$ versus the scan rate $(v),(C)$ The plot of anodic peak current versus the square root of scan rate $(\sqrt{ } v)$, (D) Variation of the logarithm of peak current (log Ipa) with the logarithm of scan rate $(\log v)$

\section{Effect of the solution $\mathrm{pH}$}

The effect of $\mathrm{pH}$ on the electrode response and the oxidation potential were investigated by the $\mathrm{CV}$ technique in the $\mathrm{pH}$ range of 5.5 to 8.0. As shown in Figure 7, the anodic peak current of UA increased with increase in $\mathrm{pH}$ from 5.5 to 7.0 and then decreased for further increase in $\mathrm{pH}$. Furthermore, the Epa vs. pH graph Figure 7 clearly shows that the anodic peak potential (Epa) shifts to negative value with increase in $\mathrm{pH}$ with the slope of 56.9 $\mathrm{mV} / \mathrm{pH}$. The slope value is close to the theoretical value of $59 \mathrm{mV} / \mathrm{pH}$ for an oxidation reaction where equal number of electrons and protons are involved ${ }^{23,24}$.

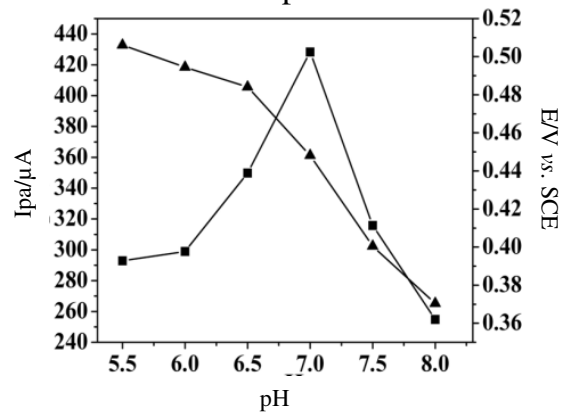

Figure 7. The plot of anodic peak current, peak potential versus $\mathrm{pH}$ for $1 \mathrm{mM}$ uric acid on poly(benzoic acid) modified carbon paste electrode at different $\mathrm{pH}$ (a-f : 5.5, 6, 6.5, 7, 7.5 and 8) at the scan rate of $50 \mathrm{mV} / \mathrm{s}$

Simultaneous determination of UA, AA and DA in the same sample at poly(benzoic acid) modified carbon paste electrode by cyclic voltammetry

Sensitivity and selectivity of PBA/CPE was tested by observing the electrochemical behavior of a mixture of $4.2 \mathrm{mM} \mathrm{AA}, 0.08 \mathrm{mM}$ DA and $0.4 \mathrm{mM}$ UA using CV in the potential window of $-0.1 \mathrm{~V}$ to $0.6 \mathrm{~V}$ at the scan rate of $100 \mathrm{mV} / \mathrm{s}$ in $\mathrm{pH} 7 \mathrm{PBS}$. Figure $8(\mathrm{~A})$ shows the $\mathrm{CV}$ at both BCPE (solid line curve) and PBA/CPE (dashed line curve). From the figure it is evident that, BCPE could not properly resolve the three components of the mixture resulting in a broad voltammetric signal for DA and AA at $0.5214 \mathrm{~V}$ indicating the 
co-oxidation. The fouling of BCPE surface by the oxidation products of AA and DA may also be the reason for a single voltammetric peak for DA and $\mathrm{AA}^{25}$. Whereas at PBA/CPE the three components were well resolved. The anodic peak potentials for AA, DA and UA were $0.4173 \mathrm{~V}, 0.2277 \mathrm{~V}$ and $-0.0079 \mathrm{~V}$ respectively at modified electrode. The anodic peak potential separation of DA-AA and UA-DA were $0.1901 \mathrm{~V}$ and $0.2356 \mathrm{~V}$ respectively, which were large enough to allow the simultaneous determination of AA, DA and UA.
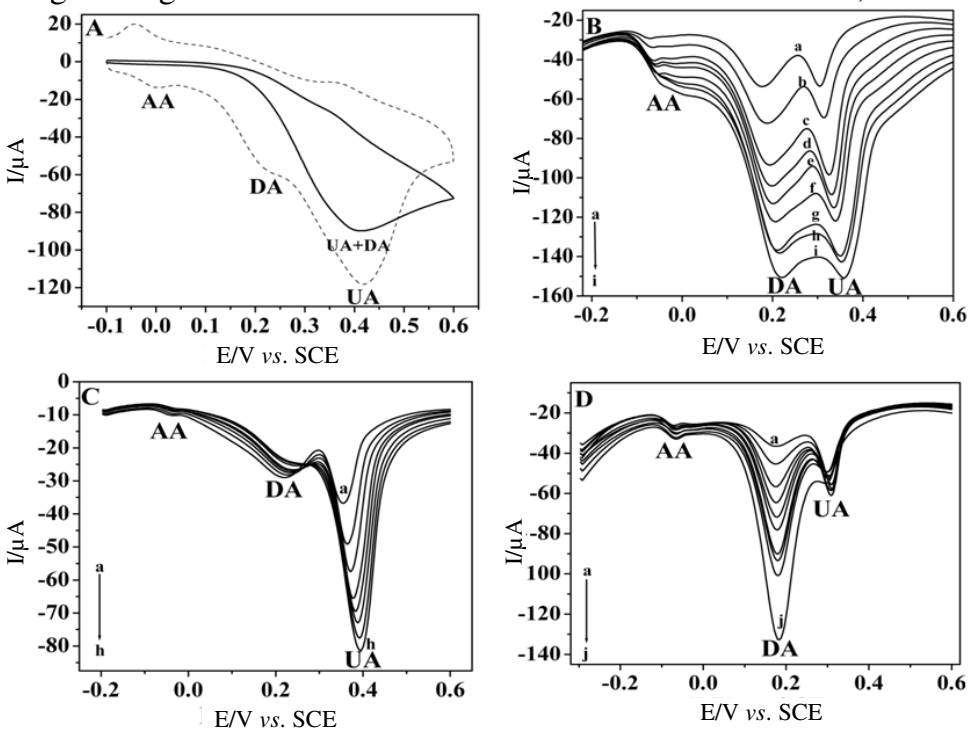

Figure 8. (A) Cyclic voltammogram for simultaneous determination of $4.2 \mathrm{mM} \mathrm{AA}, 0.08$ mM DA and $0.4 \mathrm{mM}$ UA mixture at bare carbon paste electrode (solid line curve) and at poly (benzoic acid) modified carbon paste electrode (dashed line curve) in $0.1 \mathrm{M}$ phosphate buffer solution of $\mathrm{pH} 7$ at the scan rate of $50 \mathrm{mV} / \mathrm{s}$, (B) Differential pulse voltammograms of AA, DA and UA mixture by varying the concentrations of all the components (a-i) : AA (1 to $6.6 \mathrm{mM})$, DA $(0.02$ to $0.13 \mathrm{mM})$ and UA $(0.1$ to $0.66 \mathrm{mM}),(\mathrm{C})$ Differential pulse voltammogram of AA, DA and UA mixture by varying the concentration of UA (a-h: 0.1 $\mathrm{mM}$ to $0.96 \mathrm{mM}$ ) keeping $\mathrm{AA}$ and DA concentrations fixed at $1 \mathrm{mM}$ and $0.02 \mathrm{mM}$ respectively, (D) Differential pulse voltammogram of AA, DA and UA mixture by varying the concentration of DA (a-j : $0.02 \mathrm{mM}$ to $0.20 \mathrm{mM}$ ) keeping AA and UA concentrations fixed at $1 \mathrm{mM}$ and $0.1 \mathrm{mM}$ respectively.

Simultaneous determination of AA, DA and UA was also carried out using differential pulse voltammetry in the potential range of $-0.3 \mathrm{~V}$ to $0.6 \mathrm{~V}$ in $\mathrm{pH} 70.1 \mathrm{M}$ PBS. In the first case, the concentrations of all the three components were simultaneously varied and recorded the DPV. It is shown in Figure 8(B). Concentrations of AA, DA and UA were varied in the range $1 \mathrm{mM}$ to $6.6 \mathrm{mM}, 0.02 \mathrm{mM}$ to $0.13 \mathrm{mM}$ and $0.1 \mathrm{mM}$ to $0.66 \mathrm{mM}$ respectively. The oxidation peaks were well separated $(\triangle \mathrm{Ep}$ for DA-AA is $0.1339 \mathrm{~V}$ and UA-DA is $0.2582 \mathrm{~V}$ ) and also the anodic peak current for the three components increased proportionately with the increase in concentration. This indicates that the electrode has excellent selectivity and sensitivity in the various concentration intervals.

In the second case each one of the components of the mixture was varied keeping the other two components fixed. Figure $8(\mathrm{C})$ represents the DPV for UA variation $(0.1 \mathrm{mM}$ to $0.96 \mathrm{mM})$ keeping AA $(1 \mathrm{mM})$ and DA $(0.02 \mathrm{mM})$ concentrations fixed. Similarly, Figure 8(D) 
shows the DPV for DA variation $(0.02 \mathrm{mM}$ to $0.2 \mathrm{mM})$ keeping AA $(1 \mathrm{mM})$ and UA $(0.1$ $\mathrm{mM}$ ) concentrations fixed. In all these DPVs, the anodic peak current of the component whose concentration was varied changed proportionately and for the remaining two components unchanged. Also, the selectivity was excellent indicating that irrespective of the concentrations of the other components, the component under observation can be detected very effectively.

\section{Effect of UA concentration on modified electrode}

Since, DPV has higher current sensitivity and better resolution than CV, it was employed in the estimation of linear range, detection limit and quantification of UA. As per the electrochemical response obtained (Figure 9(A)) the anodic peak current increased linearly with increase in concentration of the analyte UA in the concentration range of $1 \mu \mathrm{M}$ to $90 \mu \mathrm{M}$. Figure 9 (B) is the plot of Ipa $v s$. concentration of UA. It is linear (Ipa $=0.0211 \times \mathrm{C}+$ $2.46903 \times 10^{-7}$ ) with correlation coefficient of 0.9983 . From this plot, the detection limit (LOD) and quantification limit (LOQ) of PBA/CPE were found ${ }^{26,27}$ for UA using the formulae (2) and (3).
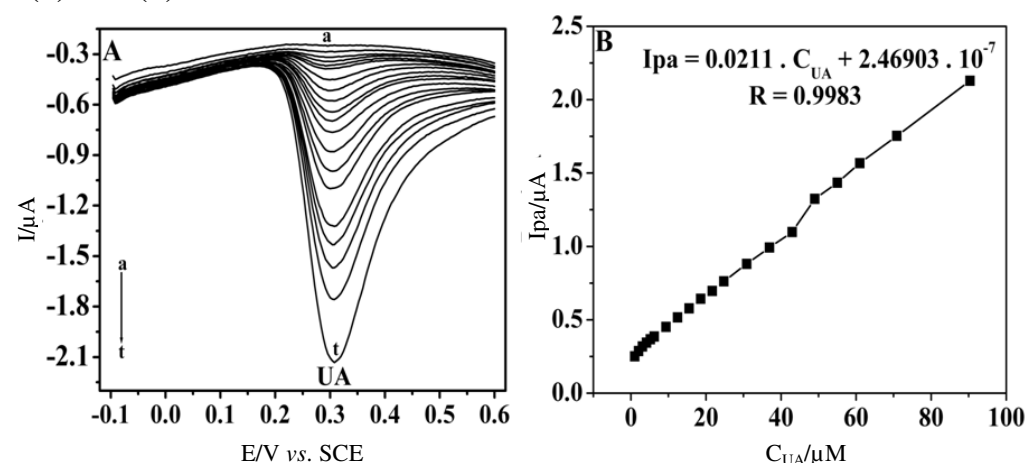

Figure 9. (A) Differential pulse voltammograms for various concentrations of UA ( $1 \mu \mathrm{M}$ to $90 \mu \mathrm{M}$ ) at poly(benzoic acid) modified carbon paste electrode in $0.1 \mathrm{M}$ phosphate buffer solution of $\mathrm{pH} 7$ at the scan rate of $50 \mathrm{mV} / \mathrm{s}$, (B) The plot of anodic peak current versus concentration of UA

$$
\begin{aligned}
& \mathrm{LOD}=3 \mathrm{~S} / \mathrm{M} \\
& \mathrm{LOQ}=10 \mathrm{~S} / \mathrm{M}
\end{aligned}
$$

Where $\mathrm{S}$ is the standard deviation and $\mathrm{M}$ is the slope .The detection limit and quantification limit were found to be $3.33 \times 10^{-7} \mathrm{M}(0.333 \mu \mathrm{M})$ and $1.11 \times 10^{-6} \mathrm{M}(1.11 \mu \mathrm{M})$ respectively which is good enough for its application in the field of medicine. Comparison of detection limit of PBA/CPE with other electrodes for the detection of UA is shown in the Table 1.

Table 1. Comparison of linear range and detection limit of PBA/CPE with other electrodes for the detection of UA

\begin{tabular}{cccc}
\hline Modified electrode & Linear range, mol L & LOD, mol L & Reference \\
\hline Plmox-GO & $3.6 \times 10^{-6}-2.5 \times 10^{-4}$ & $5.9 \times 10^{-7}$ & 28 \\
$\mathrm{SnO}_{2}$-P/MWCNTs/CPE & $3.0 \times 10^{-6}-2.0 \times 10^{-4}$ & $1.0 \times 10^{-6}$ & 29 \\
$\mathrm{M}^{-}$-meso-PAN/GCE & $1.0 \times 10^{-5}-3.0 \times 10^{-4}$ & $5.2 \times 10^{-6}$ & 30 \\
GNPs/Plm/GCE & $6.0 \times 10^{-6}-4.9 \times 10^{-4}$ & $5.0 \times 10^{-7}$ & 31 \\
CP/CSBCE & $1.0 \times 10^{-3}-1.0 \times 10^{-8}$ & $8.0 \times 10^{-9}$ & 32 \\
PAO/GH/GCE & $1.0 \times 10^{-7}-1.0 \times 10^{-3}$ & $2.0 \times 10^{-8}$ & 33 \\
PBA/CPE & $1.0 \times 10^{-6}-9.0 \times 10^{-5}$ & $3.3 \times 10^{-7}$ & This work \\
\hline
\end{tabular}




\section{Real sample analysis - analysis of uric acid in human urine}

Practical applications of PBA/CPE were demonstrated by quantitative determination of UA in human urine sample. $2 \mathrm{~mL}$ of urine sample without any pretreatment was diluted to $100 \mathrm{~mL}$ with $0.1 \mathrm{M} \mathrm{pH} 7 \mathrm{PBS}$. Each time, $24 \mathrm{~mL}$ of this solution was added with different volumes of UA solution of known concentration to obtain different concentrations of spiked UA. These solutions were analysed by CV using modified electrode by carrying out each experiment three times. The results are shown in Table 1. For determining the concentration of UA, the calibration plot was used which was constructed for the determination of effect of UA on the modified electrode. The results are quite consistent with the expected values with average recovery of $100.5 \%$ suggesting that the modified electrode has a good precision and proposed method can be effectively applied for the determination of UA in real samples.

Table 2. Determination of UA in human urine sample

\begin{tabular}{ccccc}
\hline Sample & Spiked UA, $\mathrm{mmol} \mathrm{L}^{-1}, \mathrm{~L}^{-1}$ & UA found(mmol & Recovery, \% & RSD, \% \\
\hline \multirow{3}{*}{ Urine } & 0.1 & 0.099 & 99 & 0.98 \\
& 0.2 & 0.207 & 103.5 & 5.11 \\
& 0.3 & 0.297 & 99 & 7.78 \\
\hline
\end{tabular}

\section{Conclusion}

The electropolymerisation of benzoic acid on the surface of CPE produced a stable polymeric film. The resulting poly (benzoic acid) modified carbon paste electrode not only exhibited strong electro catalytic activity for the oxidation of AA, DA and UA but also resolved the overlapping anodic peaks of these compounds, thus proved to be very selective. The high selectivity and sensitivity together with the ease of preparation and surface regeneration of the modified electrode could make this electrode to be useful in the construction of sample devices for the simultaneous determination of UA in the presence of interfering compounds such as AA and DA in the field of electro analytical chemistry and medicine.

\section{References}

1. Andreadou E, Nikolaou C, Gournaras F, Rentzos M, Boufidou F, Tsoutsou A, Zournas C, Zissimopoulos V and Vassilopoulos D, Clinical Neurology Neurosurgery, 2009, 111, 724-728; DOI:10.1016/j.clineuro.2009.06.012

2. Popa E, Kubota Y, Tryk D A and Fujishima A, Anal Chem., 2000, 72(7), 1724-1727; DOI:10.1021/ac990862m

3. Zhang L and Lin X, Analyst, 2001, 126, 367-370.

4. Jeevan Jyothi P, Gangadhara Reddy K, Prabhakar Rao V, Lavanya M and Madhavi G, Chem Sci Trans., 2015, 4(2), 541-551; DOI:10.7598/cst2015.1012

5. $\mathrm{Hu} \mathrm{G}, \mathrm{Ma} \mathrm{Y}$, Guo $\mathrm{Y}$ and Shao S, Electrochim Acta, 2008, 53(22), 6610-6615; DOI:10.1016/j.electacta.2008.04.054

6. Grabowska I, Chudy M, Dybko A and Brzoz Z, Sens Actuators B, 2008, 130(1), 508513; DOI:10.1016/j.snb.2007.09.051

7. Larsen T and Moyes K M, J Dairy Res., 2010, 77(4), 438-444; DOI:10.1017/S0022029910000580

8. Rocha D L and Rocha F R P, Microchem J., 2010, 94(1), 53-59; DOI:10.1016/j.microc.2009.08.010

9. Manzoori J L, Jouyban A, Amjadi M and Soleymani J, Luminescence, 2011, 26(2), 106-111; DOI:10.1002/bio.1191 
10. Sun Y H, Zhang Z J, Xi Z J and Shi Z L, Luminescence, 2010, 25(1), 61-66; DOI:10.1002/bio.1145

11. Dutra R F, Moreira K A, Oliveira M I P, Araujo A N, Montenegro M C B S, Filho J L L and Silva V L, Electroanalysis, 2005, 17(8), 701-705; DOI:10.1002/elan.200403142

12. Uysal U D, Oncu-kaya E M and Tuncel M, Chromatographia, 2010, 71(7), 653-658; DOI:10.1365/s10337-010-1555-4

13. Prakash S, Chakrabarty T, Rajesh A M and Shahi V K, Measurement, 2012, 45(3), 500-506; DOI:10.1016/j.measurement.2011.10.022

14. Chao M Y, Ma X Y and Li X, Int J Electrochem Sci., 2012, 7, 2201-2213.

15. O'Neill R D, Analyst, 1994, 119(5), 767-779.

16. Razmi H, Agazadeh M and Habibi A B, J Electroanal Chem., 2003, 547(1), 25-30; DOI:10.1016/S0022-0728(03)00175-X

17. Selvaraju T and Ramaraj R, Electrochemistry Communications, 2003, 5(8), 667-672; DOI:10.1016/S1388-2481(03)00151-6

18. Adams R N, Analy Chem., 1958, 30, 1576; DOI:10.1021/ac60141a600

19. Chandrashekar B N and Swamy B E K, Analy Methods, 2012, 4, 849-854; DOI:10.1039/C2AY05632A

20. Stozhko N Y, Malakhova N A, Fyodorov M V and Brainina K Z, J Solid State Electrochem., 2008, 12(10), 1185-1204; DOI:10.1007/s10008-007-0472-4

21. Ates M, Castillo J, Sarac A S and Schuhmann W, Microchim.Acta, 2008, 160(1), 247-251; DOI:10.1007/s00604-007-0837-5

22. Ongera Gilbert, Kumara Swamy B E, Umesh Chandra and Sherigara B S, Int J Electrochem Sci., 2009, 4(4), 582-591.

23. Baby Gayathri S, Kamaraj P, Arthanareeswari M and Devi kala S, Chem Sci Trans., 2014, 3(4), 1446-1454; DOI:10.7598/cst2014.926

24. Gangadhara Reddy K, Madhavi G, Kumara Swamy B E, Sathish Reddy, Vijaya Bhaskar Reddy A and Madhavi V, J Mole Liq., 2013, 180, 26-30; DOI:10.1016/j.molliq.2012.12.032

25. Madhavi G, Damodar J, Mohan S K and Reddy S J, Bull Electrochem., 1999, 15(12), 535-538.

26. Lavanya M, Veera Manohara Reddy Y, Prabhakara Rao V and Madhavi G, Chem Sci Trans., 2014, 3(4), 1404-1414; DOI:10.7598/cst2014.916

27. Veera Manohara Reddy Y, Prabhakara Rao V, Vijaya Bhaskar Reddy A, Lavanya M, Venu $\mathrm{M}$ and Madhavi G, Mater Sci Engg C, 2015, 57, 378-386; DOI:10.1016/j.msec.2015.08.005

28. Liu X F, Zhang L, Wei S P, Chen S H, Ou X and Lu Q Y, Biosens Bioelectron 2014, 57, 232-238; DOI:10.1016/j.bios.2014.02.017

29. Sun D M, Zhao Q, Tan F, Wang X C and Gao J S, Anal Methods, 2012, 4, 32833289; DOI:10.1039/C2AY25401H

30. Prathap M U A and Srivastava R, Sensors Actuators B, 2013, 177, 239-250; DOI:10.1016/j.snb.2012.10.138

31. Wang C, Yuan R, Chai Y Q, Chen S H, Hu F X and Zhang M H, Anal. Chim Acta, 2012, 741(1), 15-20; DOI:10.1016/j.aca.2012.06.045

32. Amiri M, Bezaatpour A, Pakdel Z and Nekoueian K, J. Solid State Electrochem., 2012, 16(6), 2187-2195; DOI:10.1007/s10008-011-1636-9

33. Wang Z H, Xia J F, Zhu LY, Zhang F F, Guo X M, Li Y H and Xia Y Z, Sensors Actuators B, 2012, 161(1), 131-136; DOI:10.1016/j.snb.2011.09.082 